\title{
PARA ALÉM DA QUESTÃo: (NÃo) ENSINAR GRAMÁTICA?
}

\section{BEYOND THE QUESTION: TO TEACH OR NOT TO TEACH GRAMMAR?}

\author{
Edair Maria Görski | Lattes | edagorski@hotmail.com \\ Universidade Federal de Santa Catarina
}

\author{
Mara Aparecida Siqueira | Lattes | marasiqueira@yahoo.com.br \\ Fundação Catarinense de Educação Especial
}

Resumo: Este texto apresenta reflexões sobre o que, para que e como ensinar gramática, (i) abordando diferentes concepções de linguagem, língua e gramática;(ii) discutindo a necessidade ou não de o professor de Língua Portuguesa guiar-se por determinada concepção; e (iii) discorrendo sobre qual a finalidade do ensino de gramática e qual a maneira mais adequada de tratá-la no âmbito escolar. Seu desenvolvimento é norteado pelas seguintes questões: 1) É necessário que o professor da Educação Básica tenha conhecimento de diferentes concepções de linguagem, de língua e de gramática? 2) É necessário que o professor assuma uma dada concepção de gramática, de linguagem e de língua e paute suas aulas exclusivamente por essa concepção? As reflexões são desenvolvidas no sentido de responder afirmativamente a primeira questão, e negativamente a segunda. Ao final, sugerimos uma abordagem ampla de gramática do uso, que agregue aspectos conceituais de diferentes teorias linguísticas, contemplando a língua como sistema heterogêneo sócio-historicamente constituído, a tensão entre estabilidade e instabilidade nas relações entre formas e funções, e o ensino de gramática contextualizada, mediante atividades linguísticas, epilinguísticas e metalinguísticas. Consideramos que tal abordagem atenta para o desenvolvimento da competência comunicativa do aluno, tendo em vista a formação do sujeito-cidadão. Para dar conta da tarefa proposta, buscamos respaldo na voz de linguistas e de gramáticos com formação linguística e/ou filológica que têm se voltado, direta ou indiretamente, a esse assunto; levamos em consideração, também, alguns documentos oficiais e discussões com professores do Ensino Fundamental no âmbito do PROFLETRAS.

Palavras-chave: Concepções de linguagem, língua e gramática; Ensino; Competência comunicativa; Gramática do uso. 
Abstract: This text presents reflections on what, for what purpose and how teaching grammar by (i) approaching different conceptions of language and grammar; (ii) discussing if the teacher of Portuguese Language needs or not to be guided by a certain conception; and by (iii) discussing the purposes of teaching grammar and what is the most adequate manner for dealing with it at school. This text is guided by the following questions: 1 ) Is it necessary that the teacher of Basic Education knows different conceptions of language and grammar? 2) Is it necessary that the teacher assumes one conception of language and grammar, and guides his/her classes exclusively by that conception? The reflections are developed in the sense of answering the first question affirmatively and the second question negatively. We argue in favor of an wide approach of grammar in use that assembles conceptual aspects from different linguistic theories contemplating language as a socio-historically constructed heterogeneous system, as tension between stability and instability in the relations of forms and functions, and that contemplates the teaching of contextualized grammar, through linguistic, epilinguistic and metalinguistic activities. We considered such an approach looks at developing the students' communicative competence aiming the formation of the subject-citizen. To carry out the proposed task, we heard linguists and grammarians with linguistic and/or philological formation that directly or indirectly have been paying attention to this matter, as well as in official documents and discussions with Elementary School teachers in the context of PROFLETRAS.

Keywords: Conception of language and grammar; Teaching; Communicative competence; Grammar in use.

\section{Introdução ${ }^{1}$}

Um rastreamento em documentos oficiais ${ }^{2}$ que parametrizam o ensino de Língua Portuguesa, com o objetivo de perceber o lugar destinado à gramática, indica que (i) são infrutíferas e mesmo sem sentido discussões em torno de se ensinar ou não se ensinar gramática na escola; (ii) as discussões relevantes dizem respeito a que gramática ensinar, para que e como ensiná-la. Nessa direção, são ilustrativas as seguintes passagens dos documentos consultados:

\footnotetext{
${ }^{1}$ Agradecemos as contribuições dos pareceristas anônimos. Eventuais falhas remanescentes são de nossa responsabilidade.

2 Foram examinados os Parâmetros Curriculares Nacionais (PCN) (BRASIL, 1998) e a Proposta Curricular de Santa Catarina (PCSC) (SANTA CATARINA, 2014). Vale observar que desde a década de 1980 essas propostas curriculares vêm sendo coletivamente construídas e revisadas, por equipes especializadas, com implementação gradativa no âmbito escolar, em nível nacional e estadual, respectivamente.
} 
[a gramática], ensinada de forma descontextualizada, tornou-se emblemática de um conteúdo estritamente escolar, do tipo que só serve para ir bem na prova e passar de ano - uma prática pedagógica que vai da metalíngua para a língua por meio de exemplificação, exercícios de reconhecimento e memorização de terminologia. Em função disso, discute-se se há ou não necessidade de ensinar gramática. Mas essa é uma falsa questão: a questão verdadeira é o que, para que e como ensiná-la. (BRASIL, 1998, p. 28).

Muitos professores tendem a se mostrar seguros acerca do que não deve ser feito - uma abordagem gramatical normativista tomada fora do uso -, mas parecem inseguros em relação ao que precisa ser feito - o trabalho com análise linguística. Assim, dois comportamentos vêm sendo sinalizados na ação docente em Línguas: ou a inaceitável manutenção de uma abordagem gramatical normativista destituída de sentido, ou o também inaceitável absoluto apagamento do trabalho com conhecimentos gramaticais na escola. (SANTA CATARINA, 2014, p. 131, grifo no original).

Uma vez que não se coloca em discussão o fato de que a gramática tem lugar garantido nas aulas de Língua Portuguesa, voltamos nossa atenção ao item (ii), que envolve concepções de gramática (e, por extensão, de linguagem e de língua) e aspectos metodológicos.

O desenvolvimento deste texto é norteado pelas seguintes questões: 1) É necessário que o professor da Educação Básica tenha conhecimento de diferentes concepções de linguagem, de língua e de gramática? 2) É necessário que o professor assuma uma dada concepção de gramática, de linguagem e de língua e que paute suas aulas exclusivamente por essa concepção? Nosso propósito é desenvolver uma reflexão no sentido de dar uma resposta afirmativa para a primeira questão, mas não para a segunda, considerando implicações pedagógicas dessa tomada de posição. Como resultado, sugerimos um tipo de abordagem para o ensino a partir de uma análise gramatical contextualizada.

Para dar conta da tarefa, buscamos, além dos documentos oficiais mencionados, respaldo na voz de linguistas e de gramáticos com formação linguística e/ou filológica que têm se voltado, direta ou indiretamente, a esse assunto. Esperamos, pois, que este trabalho contribua para elucidar certos pontos nodais e para suscitar discussões críticas tanto entre docentes como entre estudantes e demais interessados no ensino de gramática. ${ }^{3}$

O texto está assim organizado: na primeira seção, são expostas diferentes concep-

\footnotetext{
${ }^{3}$ As reflexões trazidas neste texto agregam discussões com professores de Língua Portuguesa do Ensino Fundamental realizadas na disciplina de Gramática, variação e ensino, do PROFLETRAS, e discussões que foram amadurecidas pelas autoras em encontros de orientação de dissertação de mestrado. Um desenho dessa disciplina pode ser conferido no texto de Vieira (2017), que trata de três eixos para o ensino de gramática: gramática e variação, gramática e atividade reflexiva, gramática e construção de sentido no texto.
} 
ções de linguagem, de língua e de gramática; na segunda seção, é brevemente contraposto o modelo de gramática tradicional a modelos linguísticos de gramática; na terceira seção, é apresentada uma proposta de abordagem para o ensino de gramática a partir da língua em uso; por último, são discutidas algumas implicações pedagógicas dessa proposta, seguidas de considerações finais.

\section{Concepções de linguagem, de língua e de gramática}

Os termos linguagem, língua e gramática remetem a significações distintas a depender da perspectiva teórica a partir da qual são definidos. ${ }^{4}$

Em termos gerais, há três concepções de linguagem que circulam de forma recorrente na literatura da área: (i) linguagem como representação (espelho) do mundo e expressão do pensamento; (ii) linguagem como instrumento de comunicação; e (iii) linguagem como forma ou ação ou lugar de interação (GERALDI, 1984; KOCH, 1992; TRAVAGLIA, 2009; entre outros autores). A essas, agrega-se ainda uma quarta concepção: (iv) linguagem como inata e universal (LOBATO, 1986). Correlatas a essas concepções de linguagem, temos, grosso modo, as seguintes concepções de língua: ${ }^{5}$ (i) língua como formas de expressão; (ii) língua como código; (iii) língua como conjunto de usos concretos; e (iv) língua como conhecimento internalizado. O Quadro 1 correlaciona essas concepções, descrevendo-as, brevemente.

Quadro 1. Concepções de linguagem, de língua ${ }^{6}$

\begin{tabular}{|l|l|}
\hline Linguagem como representação (espelho) do & $\begin{array}{l}\text { Língua como formas de expressão - formas a } \\
\text { mundo e expressão do pensamento - a ex- } \\
\text { serviço da exteriorização de ideias, priman- } \\
\text { do pela organização lógica e pela clareza, } \\
\text { pressão é construída na mente, como refle- } \\
\text { xo do mundo, sendo traduzida pela lingua- } \\
\text { sem preocupação com a situação comuni- } \\
\text { cativa. }\end{array}$ \\
\hline
\end{tabular}

\footnotetext{
${ }^{4}$ Nossa intenção, nesta seção, não é aprofundar as diferentes concepções, e sim evidenciar que há uma pluralidade de significados associada a cada termo e apresentar algumas dessas concepções, especialmente aquelas identificadas como mais recorrentes nos escritos voltados ao ensino de língua.

${ }^{5}$ As três primeiras concepções de língua são caracterizadas com base em Travaglia (2009).

${ }^{6}$ Cabe salientar que as concepções de linguagem e de língua descritas não esgotam as possibilidades de enfoque, nem dão conta de todas as nuanças envolvidas em cada uma delas, e também não são necessariamente excludentes.
} 


\begin{tabular}{|c|c|}
\hline $\begin{array}{l}\text { Linguagem como instrumento de comuni- } \\
\text { cação - o falante tem em sua mente uma } \\
\text { mensagem a transmitir a um ouvinte; essa } \\
\text { mensagem é codificada e enviada através } \\
\text { de um canal para o outro, que a recebe e a } \\
\text { decodifica. }\end{array}$ & $\begin{array}{l}\text { Língua como código - conjunto de signos } \\
\text { que se combinam sistematicamente de } \\
\text { acordo com regras convencionadas. A lín- } \\
\text { gua é concebida como um sistema conven- } \\
\text { cional imanente. }\end{array}$ \\
\hline $\begin{array}{l}\text { Linguagem como forma de interação - o in- } \\
\text { divíduo realiza ações, atua sobre o interlo- } \\
\text { cutor (ouvinte/leitor) por meio da lingua- } \\
\text { gem. }\end{array}$ & $\begin{array}{l}\text { Língua como conjunto de usos - realidade } \\
\text { sócio-historicamente construída pelos in- } \\
\text { terlocutores, sujeitos que ocupam lugares } \\
\text { sociais e falam a partir desses lugares. }\end{array}$ \\
\hline $\begin{array}{l}\text { Linguagem como capacidade inata e univer- } \\
\text { sal - estrutura cognitiva que faz parte da } \\
\text { herança genética do ser humano; corres- } \\
\text { ponde ao estado mental inicial (chamado } \\
\text { de Gramática Universal), que se desenvol- } \\
\text { ve, passando por estágios sucessivos de ma- } \\
\text { turação, até atingir um estágio estável. }\end{array}$ & $\begin{array}{l}\text { Língua como conhecimento internalizado - } \\
\text { conjunto de propriedades estruturais abs- } \\
\text { tratas, complexas e altamente específicas, } \\
\text { que são conhecidas pelos indivíduos inde- } \\
\text { pendentemente do contexto. }\end{array}$ \\
\hline
\end{tabular}

Fonte: Adaptado de Görski e Freitag (2007, p. 103).

Essas noções de linguagem e de língua são correlacionadas, de modo geral, a diferentes tipos de gramática, entendida basicamente como um conjunto de regras: (i) que devem ser seguidas - normativas/prescritivas; (ii) que são seguidas - descritivas; (iii) que o falante da língua domina - internalizadas (POSSENTI, 1996). Esses tipos de regra que constituem diferentes gramáticas são, contudo, de natureza bem distinta e não se distribuem em um mesmo nível. Uma primeira distinção a ser feita diz respeito ao tipo de abordagem - implícita ou explícita. Temos, de um lado, uma abordagem teórica que concebe a gramática como implícita, internalizada ou natural; de outro lado, uma abordagem de gramática explícita, que tanto pode se correlacionar a uma concepção de linguagem como capacidade inata e universal, quanto a uma concepção de linguagem como expressão do pensamento, instrumento de comunicação, ou forma de interação. A abordagem explícita se ocupa tanto de regras de caráter normativo/prescritivo como de regras de caráter descritivo. O Quadro 2 expõe, de maneira sucinta, essas diferentes abordagens e concepções de gramática. 
Quadro 2. Abordagens e concepções de gramática

\begin{tabular}{|c|}
\hline \\
\hline $\begin{array}{l}\text { A gramática implícita/internalizada corresponde à competência linguística do falante, entendida } \\
\text { como a capacidade do indivíduo de produzir e entender um número infinito de sentenças, e de } \\
\text { julgar se elas são bem formadas ou não, a partir de um número finito de regras internalizadas. } \\
\text { Trata-se de "um conjunto (finito ou infinito) de sentenças, cada uma finita em comprimento e } \\
\text { construída a partir de um conjunto finito de elementos" (CHOMSKY, 1957, p. 13). Ou ainda: } \\
\text { "um sistema de regras, unidades e estruturas que o falante de uma língua tem programado em } \\
\text { sua memória e que lhe permite usar a língua" (PERINI, 2006, p. 23). }\end{array}$ \\
\hline Abordagem explícita \\
\hline $\begin{array}{l}\text { Gramática tradicional }(\mathrm{GT})^{7} \text { - de caráter descritivo-normativo, prescreve regras para 'falar e es- } \\
\text { crever corretamente', tomando como padrão ou modelo uma língua homogênea idealizada, a } \\
\text { partir de descrição baseada na escrita literária clássica. Segue a tradição filosófica greco-latina. }\end{array}$ \\
\hline $\begin{array}{l}\text { Gramática descritiva formal - busca descrever, cientificamente, as propriedades estruturais abs- } \\
\text { tratas da gramática implícita/internalizada. Ocupa-se da língua enquanto sistema homogêneo } \\
\text { e autônomo, desvinculado dos usuários. Limita-se ao nível gramatical da sentença. }\end{array}$ \\
\hline $\begin{array}{l}\text { Gramática descritiva funcional - busca registrar e descrever, cientificamente, diferentes varieda- } \\
\text { des da língua em uso, explicitando as regras que regem o funcionamento dos itens linguísticos } \\
\text { em todos os níveis gramaticais, incluindo o textual/discursivo. }\end{array}$ \\
\hline
\end{tabular}

Fonte: Adaptado de Görski e Freitag (2007, p. 103).

Cabe salientar que, assim como as concepções de linguagem e de língua descritas não esgotam as possibilidades de enfoque, as concepções de gramática da abordagem explícita apresentadas no Quadro 2 são, de certa forma, reducionistas e não distinguem especificidades de caráter teórico-conceitual e também metodológico envolvidas em cada tipo. $\mathrm{O}$ quadro mostra, apenas, uma sistematização de tendências mais gerais, com base no que foi exposto até o momento. A visão de Castilho (2010), apresentada a seguir, fornece algumas informações complementares a esse respeito.

Sob uma ótica distinta, Castilho (2010), em sua Nova gramática do Português Brasileiro, partindo de uma ampla revisão de teorias linguísticas e gramaticais e considerando a língua em seu dinamismo, identifica quatro grandes direções nos estudos contemporâneos, desenvolvidos à luz da linguística moderna (razão pela qual não contempla a GT entre essas tendências). O Quadro 3 mostra as direções apontadas pelo autor.

\footnotetext{
${ }^{7}$ Adiante, discutimos o uso do termo gramática tradicional e as noções nele envolvidas, bem como a relação entre GT e as chamadas gramáticas normativas.
} 
Quadro 3. Correlação entre teorias sobre a língua e a gramática

\begin{tabular}{|c|c|}
\hline $\begin{array}{l}\text { A língua como um conjunto de produtos } \\
\text { estruturados - um conjunto ordenado } \\
\text { de itens/classes relacionados entre si, } \\
\text { que se distribuem em níveis linguís- } \\
\text { ticos hierárquicos, cuja realização no } \\
\text { enunciado está sujeita a variações. }\end{array}$ & $\begin{array}{l}\text { Gramática descritiva - a partir de determinado cor- } \\
\text { pus, descreve os itens/classes linguísticos, conside- } \\
\text { rando suas relações, hierarquicamente estruturadas } \\
\text { em sentenças, com outros itens/classes. }\end{array}$ \\
\hline $\begin{array}{l}\text { A língua como um conjunto de processos } \\
\text { mentais estruturantes - um sistema di- } \\
\text { nâmico, heterogêneo e complexo, com } \\
\text { funções socialmente definidas, que se } \\
\text { fundamenta num aparato sociocogniti- } \\
\text { vo, cujas funções básicas são a de cons- } \\
\text { trução e organização do pensamento e } \\
\text { de uma visão de mundo, e a de comu- } \\
\text { nicação. }\end{array}$ & $\begin{array}{l}\text { Gramática funcional-cognitiva-concebe as estruturas } \\
\text { como dependentes de contexto, levando em conta, } \\
\text { de forma integrada, o nível sintático-semântico-dis- } \\
\text { cursivo. Considera que, na língua em uso, ao lado de } \\
\text { estruturas regulares relativamente fixadas, há emer- } \\
\text { gência de novos empregos que, gradativamente, po- } \\
\text { dem ir formando novos padrões gramaticais. }\end{array}$ \\
\hline $\begin{array}{l}\text { A língua como um conjunto de processos } \\
\text { e produtos que mudam ao longo do tem- } \\
\text { po - alia as duas direções precedentes e } \\
\text { agrega a perspectiva histórica. }\end{array}$ & $\begin{array}{l}\text { Gramática histórica - com foco na centralidade dos } \\
\text { usos, articula-se com o variacionismo e o funciona- } \\
\text { lismo; com foco na centralidade da sintaxe, articula- } \\
\text {-se com o gerativismo. }\end{array}$ \\
\hline $\begin{array}{l}\text { A língua como um conjunto de 'bons usos' } \\
\text { - trata-se de uma visão fragmentada } \\
\text { que se volta apenas para determinada } \\
\text { variedade linguística: o chamado pa- } \\
\text { drão culto. }{ }^{8}\end{array}$ & $\begin{array}{l}\text { Gramática normativa/prescritiva - considera o pa- } \\
\text { drão culto, socialmente privilegiado, desconsideran- } \\
\text { do a variedade popular. }\end{array}$ \\
\hline
\end{tabular}

Fonte: Adaptado de Castilho (2010).

O Quadro 3 requer alguns comentários adicionais. Conforme já acentuado, a opção de Castilho foi por contemplar a língua em sua dinamicidade; é nessa perspectiva, portanto, que o referido quadro deve ser examinado. Na visão do autor, a gramática descritiva, apoiada em corpus, trata da organização dos constituintes linguísticos no nível de sentença, tomando a língua como produto estruturado, cuja realização está sujeita à variação ${ }^{9}$ - nesse sentido, articula-se com uma abordagem variacionista da língua (LABOV,

\footnotetext{
${ }^{8}$ Chamamos a atenção do leitor quanto a certos termos e conceitos que são acionados ao longo do texto. $\mathrm{Na}$ literatura da área, o termo padrão culto tem sido usado como equivalente a norma culta, ou a variedade padrão, ou ainda a norma/variedade urbana de prestígio, todos eles colocando em evidência que se trata de usos efetivos da língua por um certo estrato da população. O termo se distingue, nesse sentido, de normapadrão - esta sim associada a uma língua homogênea idealizada, nos moldes da gramática tradicional (cf. Quadro 2), e não a usos. Além disso, uma atenção especial requer a palavra padrão, que pode aparecer em termos como língua padrão ou norma-padrão (com caráter normativo), como variedade padrão (com caráter descritivo), ou ainda expressando a ideia de regularidade ou recorrência como em padrão de uso (também com caráter descritivo).

9 A variação linguística pode se dar entre usos ditos cultos e populares (ex.: nós vamos/ nós vai) ou entre usos de uma mesma variedade (ex.: nós sairemos/ nós vamos sair - formas alternativas de expressar o tempo futuro na variedade culta da língua. Para uma reflexão a respeito do papel da Sociolinguística na formação dos professores de Língua Portuguesa, sugerimos a leitura do texto de Görski e Freitag (2013).
} 
2008 [1972]). A gramática funcional-cognitiva, a partir da língua em uso, amplia o escopo dos fenômenos analisados para além da sentença, considerando o nível sintático-semântico-discursivo e tomando a língua como processo - alinha-se, assim, a uma abordagem funcionalista da língua (GIVÓN, 2001; HOPPER; TRAUGOTT, 2003, entre outros).

A gramática histórica foi destacada como uma das direções nos estudos contemporâneos por conceber a língua tanto como processo quanto como produto, aliando, dessa forma, as duas primeiras e, ainda, somando a dimensão histórica. É importante salientar, conforme a descrição no quadro, que o autor evoca diferentes teorias linguísticas como ancoragem para esse tipo de gramática: se baseada nos usos, atrela-se ao variacionismo e ao funcionalismo; se baseada em propriedades estruturais abstratas da gramática, articula-se ao formalismo (CHOMSKY, 1986) - linha teórica que também pode orientar a gramática descritiva. Como o interesse de Castilho é pelos usos contextualizados, ele prioriza as abordagens variacionista e funcionalista. Na ótica variacionista, há o rompimento com (i) a identificação entre estrutura e homogeneidade; (ii) a separação dicotômica entre langue e parole e entre sincronia e diacronia. Na ótica funcionalista, a mudança é vista, basicamente, em termos de gramaticalização: um processo de regularização gradual (envolvendo um conjunto de mudanças pragmáticas, semânticas, morfossintáticas e fonológicas correlacionadas), pelo qual usos inicialmente criativos tornam-se habituais pela recorrência em determinado tipo de contexto comunicativo - aproxima-se, nessa ótica, de uma noção de "gramática emergente" (HOPPER, 1987).

Por fim, a gramática normativa/prescritiva, nos termos do autor, também concebe a língua como sistema heterogêneo, porém se ocupa de uma única variedade linguística -o padrão culto (ou norma culta, ou variedade padrão) -, normatizando usos a partir da descrição dessa variedade. É interessante atentar para a ressalva do autor, numa evidente crítica à visão de língua homogênea e idealizada: "se o padrão culto for colocado numa perspectiva científica, como uma variedade linguística entre outras, e se o relacionarmos com as situações sociais em que ele é utilizado, tudo bem, a ciência voltará a respirar aliviada. E teremos menos preconceito linguístico entre nós." (CASTILHO, 2010, p. 90).

Para os propósitos deste artigo, nos alinharemos a pressupostos que ancoram o Quadro 3 (cf. Seção 3). Antes de passarmos à explanação da proposta de abordagem para o ensino de gramática que consideramos mais adequada, julgamos conveniente abrir um espaço para refletir, particularmente, sobre os termos gramática tradicional e gramática normativa/prescritiva, e os conteúdos associados a eles, uma vez que tais termos são empregados, muitas vezes, como equivalentes. É disso que tratamos na seção a seguir. 


\section{Modelo de gramática tradicional (GT) versus modelos linguísticos de gramática}

As breves descrições de gramática tradicional e de gramática normativa/prescritiva apresentadas nos Quadros 2 e 3, respectivamente, e o imbróglio conceitual que esses termos por vezes provocam (cf. nota 8), gerando não só equívocos conceituais, mas principalmente discussões acaloradas envolvendo discriminação e preconceito linguístico, motivam esta seção.

O modelo da gramática tradicional se assenta na tradição greco-latina, atrelado a uma concepção de linguagem como representação do mundo e expressão do pensamento através de formas logicamente organizadas (a língua). Tal modelo tem caráter lógico-filosófico e se pauta principalmente na linguagem literária escrita de autores considerados exemplares (como Homero) e na arte do bem falar, a retórica, cujos padrões modelares deveriam ser preservados, garantindo-se "a memória de um passado valioso" (NEVES, 2002, p. 31-32). Nessas condições, a gramática "se institui como exposição e imposição de padrões” (NEVES, 1987, apud NEVES, 2015, p. 33). Mattos e Silva (1989, p. 14) reconhece que "o processo cumulativo que se desenvolveu durante vinte e três séculos [...] é do maior interesse para a história cultural do homem e para a percepção de como foi se construindo um campo do saber, o da reflexão sobre a linguagem humana.”

Se a GT é reconhecida como um monumento de saberes acumulados, sendo considerada até hoje como "o ponto de partida e também o pano de fundo da atividade científica e especulativa da Linguística e da Filosofia da Linguagem” (BAGNO, 2001, p. 17), qual a razão de ser tão criticada, tanto no meio acadêmico como no meio escolar?

Uma das possíveis respostas pode ser o fato de que a GT "reforça o 'dialeto da elite', [...] os padrões de uso que são próprios de uma classe dominante" (MATTOS; SILVA, 1989, p. 13). Mas, a nosso ver, a razão principal diz respeito à distinção apontada por Bagno entre o que é a GT e o que são os usos e os abusos que dela são feitos: enquanto a GT é reconhecida como um patrimônio cultural do Ocidente, certos usos que dela se fazem impõem-lhe, de forma dogmática e com distorções ideológicas, “[...] o papel de doutrina canônica, de conjunto de dogmas irrefutáveis, de verdades eternas.” (BAGNO, 2001, p. 17). Tais usos abusivos acabam se estendendo da GT para as gramáticas normativas em geral, dado o viés prescritivo que também as caracteriza. ${ }^{10}$

Isso posto, voltemos aos quadros 2 e 3. A gramática tradicional do Quadro 2aproxima-se da descrição de GT feita acima, remontando a uma fase da história do conheci-

${ }^{10}$ Considere-se que "a GT, por consubstanciar uma ideologia, não tem autor, ao contrário das gramáticas normativas [que apresentam mudanças ao longo do tempo], às quais podemos nos referir como 'a gramática de Celso Cunha', 'a gramática de Rocha Lima', 'a gramática de Cegalla' etc.” (BAGNO, 2001, p. 16). 
mento anterior à era moderna. A gramática normativa/prescritiva do Quadro 3 guarda da anterior a especificidade do uso culto, porém distancia-se daquela (que se assenta em padrões modelares derivados da escrita clássica), por situar-se no âmbito da linguística moderna, considerando a língua como um sistema heterogêneo. Por essa razão, Castilho, embora com certa cautela, a elenca entre os demais tipos de gramática, no escopo das teorias linguísticas e gramaticais.

$\mathrm{O}$ que deve ser criticado e combatido, no que diz respeito ao modelo da GT e a gramáticas normativas em geral, é o caráter dogmático e doutrinário, portanto acientífico, de que por vezes se revestem. É necessário, pois, manter uma distinção entre gramática tradicional/normativa (como doutrina) e gramática normativa/prescritiva (como conjunto de regras depreendidas do uso da norma culta da língua contemporânea), uma vez que temos, ao lado de gramáticas normativas que não ignoram os avanços nos estudos linguísticos, outras que ainda se filiam a uma tradição dogmática e excludente, assentada, via de regra, na escrita literária clássica. Tais tipos de gramática normativa se ocupam do que Faraco (2008) denomina "norma culta” e "norma curta”, respectivamente.

A título de ilustração, Cunha e Cintra, na obra Nova gramática do português contemporâneo (1985), propõem-se a uma "tentativa de descrição do português atual na sua forma culta" ( $\mathrm{p}$.XIV), considerando textos de escritores portugueses, brasileiros e africanos, sem, segundo eles, descurar da linguagem coloquial. Bechara, em sua Moderna gramática portuguesa (revista, ampliada e atualizada), reconhece aliar descrição sincrônica a uma "visão sadia da gramática normativa" (2001, p. 20). Tais manuais se enquadram no grupo de obras que Faraco (2008) considera como bons instrumentos normativos, cujos autores têm formação filológica ou linguística e buscam flexibilizar a velha "norma-padrão". ${ }^{11}$

Do panorama delineado até aqui, infere-se que é crucial não "misturar alhos com bugalhos" ao se falar em gramáticas normativas: não se deve incorrer na atitude simplista e equivocada de colocar em pé de igualdade gramática normativa (ou prescritiva) e gramática tradicional. Retomando brevemente: (i) a GT pode ser vista em dupla perspectiva - como modelo clássico assentado na filosofia greco-latina e como doutrina dogmática que impõe padrões de uso de uma certa língua; (ii) a gramática normativa, por sua vez, também pode ser vista de duas maneiras - como conjunto de regras obrigatoriamente impostas a partir de um padrão idealizado (no que se aproxima de uma doutrina, tendo em mira a noção de "norma curta") e como conjunto de regras derivadas do uso de grupos sociolinguísticos mais letrados (tendo como foco a "norma culta").Portanto, a crítica que tem sido feita indistintamente à GT e à gramática normativa deve ser direcionada para a faceta dogmática de ambas. Em outras palavras, são a GT e a gramática normativa

\footnotetext{
${ }^{11}$ Nesse grupo de boas obras de referência para questões gramaticais, Faraco (2008) inclui ainda Celso Luft, Rocha Lima, além dos dicionários Aurélio e Houaiss. Tal grupo se contrapõe, por exemplo, ao gramático Napoleão Mendes de Almeida e a certos colunistas midiáticos que raivosamente defendem a chamada "norma curta", a qual se aproxima da norma-padrão idealizada.
} 
enquanto doutrina que prega um padrão idealizado de língua, e que despreza as variedades, que devem ser combatidas.

Os avanços teóricos no campo da linguística têm repercutido na organização de compêndios gramaticais no Brasil. Em publicações relativamente recentes - Neves (2000), Azeredo (2008), Castilho (2010), Perini (2010), Bagno (2011), entre outros -, verifica-se que os fenômenos gramaticais são abordados a partir de usos linguísticos efetivos, buscando, os autores, oferecer uma descrição da estrutura e do funcionamento da língua coerentemente ancorada em pressupostos teórico-conceituais fornecidos por diferentes áreas da linguística. Uma breve apresentação de cada uma dessas gramáticas é exposta a seguir, destacando-se o objetivo e o tipo de norma abordada.

Quadro 4. Gramáticas com embasamento linguístico ${ }^{12}$

A Gramática de usos do português, de Neves (2000, p. 14), tem como objetivo “[...] prover uma descrição do uso efetivo dos itens da língua, compondo uma gramática referencial do português." Detém-se em corpus de língua escrita atual, considerando gêneros textuais diversificados, de registro mais monitorado.

A Gramática Houaiss da Língua Portuguesa, de Azeredo (2008), propõe-se, para além de uma descrição do uso linguístico, a uma reflexão sobre o funcionamento da linguagem verbal, considerando-a como forma de organização do conhecimento, meio de codificação e forma de atuação interpessoal. Contempla a variedade padrão escrita do português em uso no Brasil, desde a segunda metade do século XIX.

A Nova gramática do português brasileiro, de Castilho (2010), aborda a língua em seu dinamismo, abrangendo a história da língua, um debate sobre teorias linguísticas e concepção de língua, e uma descrição do funcionamento dos níveis da fonologia, morfologia, morfossintaxe, semântica e pragmática. Trata-se de uma descrição do português brasileiro urbano falado, fruto de cinquenta anos de pesquisa, conforme ressalta o autor, em que ele não só expõe, mas também problematiza os achados da ciência linguística atual.

A Gramática do português brasileiro, de Perini (2010, p. 18), parte do pressuposto de que "a gramática é uma disciplina científica, tal como a astronomia, a química, a história ou a geografia”, que oferece uma visão da estrutura e do funcionamento da língua. É voltada para a descrição do português brasileiro $(\mathrm{PB})$ falado, com ênfase na sintaxe e na semântica da oração.

A Gramática pedagógica do português brasileiro, de Bagno (2011, p. 26), propõe-se como um livro "auxiliar para a tarefa de promoção da reflexão sobre a língua e a linguagem em sala de aula." Baseia-se em usos linguísticos contemporâneos, considerando fenômenos de variação e mudança; prioriza as variedades urbanas de prestígio e gêneros textuais escritos mais monitorados, contrapondo-se fortemente ao ensino da "norma padrão".

Fonte: Adaptado de Siqueira (2016)

12 Poderíamos acrescentar, a esse rol, a gramática de Bechara (2001), tida como representativa da passagem de uma tradição prescritiva para uma abordagem mais sintonizada com os avanços da linguística moderna. 
Note-se que as obras de Neves, Azeredo e Bagno contemplam a variedade padrão (ou norma culta) escrita - a de Azeredo abarca textos desde o século XIX e as demais concentram-se em textos contemporâneos. Já as de Castilho e Perini se voltam para o português falado no Brasil. Nenhuma delas se associa à norma-padrão, e nenhuma delas se apresenta como normativa, e sim como descritiva.

O leque aberto até aqui evidencia quão inapropriado pode ser falar em $a$ gramática, posto que existem diferentes tipos de gramática, identificados com base na natureza de cada uma. Isso nos reporta à passagem, na introdução deste artigo, que pontua que as discussões relevantes, em relação ao ensino de gramática, dizem respeito a que gramática ensinar, para que e como ensiná-la. ${ }^{13}$

\section{Por uma abordagem do ensino de gramática a partir da língua em uso}

Para orientar esta seção, retomamos nossa questão 2): É necessário que o professor assuma uma dada concepção de gramática, de linguagem e de língua e que paute suas aulas exclusivamente por essa concepção? É na direção de uma resposta negativa a essa questão que buscamos argumentar a seguir.

Vimos, nas seções precedentes, diferentes concepções de gramática associadas a diferentes concepções de linguagem/língua. ${ }^{14}$ Indicamos, também, que os pressupostos que fundamentam o Quadro 3, que contempla a língua em seu dinamismo, seriam considerados em nossa proposta para o ensino de gramática. Ocorre que o Quadro 3 sintetiza quatro diferentes direções que correlacionam, contemporaneamente, teorias sobre a língua e a gramática, colocando em foco diferentes tipos de gramática: descritiva, funcional-cognitiva, histórica e normativa. ${ }^{15}$ Como fica o professor de Língua Portuguesa diante desse cenário? Deve ater-se à descrição gramatical, seja de fenômenos categóricos ou variáveis, e ignorar a prescrição? Deve ou não atentar para fenômenos de mudança linguística? Deve limitar-se ao nível da sentença ou deve considerar os níveis de forma integrada (sintático-semântico-discursivo)? Deve ocupar-se apenas de estruturas regulares e

13 Sobre diferentes concepções de gramática e ensino, ver também o texto de Barbosa (2014) Saberes gramaticais na escola.

${ }^{14}$ Nem sempre os autores da área fazem distinção entre os termos linguagem e língua, optando, muitas vezes, pela grafia língua(gem). Utilizaremos a forma combinada linguagem/língua quando julgarmos irrelevante a distinção

15 Ressalve-se, como já apontado, que esses tipos de gramática focalizados por Castilho (2010) privilegiam a língua efetivamente em uso e não a gramática internalizada, concepção que é contemplada em abordagens formais, estando fora do escopo deste artigo. Para o leitor interessado em ampliar o leque de perspectivas de abordagem gramatical, há uma série de trabalhos voltados à questão do ensino de gramática que se alinham basicamente a uma abordagem formal da língua, entre os quais se destacam: Martins (2013), Gramática e ensino; Pires de Oliveira e Quarezemin (2016), Gramáticas na escola; Pilati (2017), Linguística, gramática e aprendizagem ativa. 
fixadas na língua ou considerar também usos emergentes? Deve ter a preocupação de não misturar teorias linguísticas? Tais indagações, entre outras, alimentam a presente seção.

A passagem a seguir, extraída da Gramática Houaiss da Língua Portuguesa, lança luz na direção que nos propomos a trilhar. A história dos estudos gramaticais é, também, a história da insatisfação
dos estudiosos da linguagem com os modelos descritivos construídos
por eles. Toda verdade é provisória - esta é, talvez, a única certeza que
fica quando observamos a maneira pela qual o conhecimento humano
é construído no curso da história. Não pode ser diferente quando o
assunto é a linguagem: nenhum modelo de análise, por mais refinado
e complexo que seja, consegue abarcar toda a sua complexidade. Desta
constatação derivam necessariamente dois postulados: (a) uma análise
abrangente do funcionamento da língua sempre dependerá da conciliação
de conceitos emprestados a diferentes perspectivas teóricas; (b) qualquer
modelo descritivo tem limitações; portanto, é natural que encaremos
qualquer análise como um corpo de afirmações sujeito a reformulação.
(AZEREDO, 2008, p. 31 ).

O trecho anterior diz respeito ao estudo científico da linguagem/língua, desvelando seu caráter dinâmico, provisório e lacunar; em razão disso, o autor sugere a necessidade de conciliações teórico-conceituais para dar conta de análises mais abrangentes. No que tange à concepção de linguagem/língua assumida em sua obra, o autor mantém-se fiel à ideia de conciliação, aproximando-se da descrição tripartite apresentada no Quadro 1 (excluída a linguagem como capacidade inata):

Enfatizando sempre o dom da palavra como traço singular da espécie humana, empenhamo-nos em refletir sobre o funcionamento da linguagem verbal no seu tríplice papel (a) de forma de organização do conhecimento (conceptualização e categorização da experiência do mundo), (b) do meio de codificação do conhecimento em enunciados/ textos (expressão) e (c) de forma de atuação interpessoal (comunicação). (AZEREDO, 2008, p. 25).

Castilho compartilha dessa visão conciliatória. Considerando a língua como um sistema complexo, cujos elementos são adaptáveis e estão em construção, admite, citando Cilliers (2000, p. viii-ix; 23), que "ao tratar de fenômenos complexos nenhum método revelará por si mesmo o objeto por inteiro" (CASTILHO, 2010, p. 63). Por isso, segundo o autor, "não poderemos nos ater a um modelo teórico apenas. A complexidade linguística põe em cheque uma afirmação constantemente repetida entre nós acerca da necessidade de consistência teórica e da proibição de posições ecléticas.” 
Se no campo dos estudos gramaticais os modelos teóricos apresentam limitações, o que se pode dizer em relação ao ensino de gramática? Nesse âmbito, particularmente no Ensino Fundamental, os postulados descritos nas citações de Azeredo e de Castilho ganham ainda maior relevo: a nosso ver, não se deve submeter o tratamento gramatical a um modelo teórico específico, sob pena de deixar transparecer uma visão fragmentada e/ ou enviesada do funcionamento da língua.

A partir dessas reflexões, retomamos, das concepções de linguagem/língua e de gramática expostas anteriormente, os conceitos que julgamos relevantes e pertinentes a um ensino "produtivo" de gramática, aquele que, nos termos de Travaglia (2009), visa a desenvolver novas habilidades linguísticas. Expandindo essa noção, diríamos: aquele que visa a contribuir para o desenvolvimento da "competência comunicativa", criando condições para a formação do aluno como sujeito-cidadão. E aqui entramos no para que ensinar gramática, o que repercute diretamente em que gramática ensinar.

Entendemos por competência comunicativa a capacidade de adequar a linguagem a diferentes situações de interlocução.

\begin{abstract}
Essa noção evoca e, de certa maneira, se sobrepõe a outros tipos de competência: competência gramatical (habilidade de operar com estruturas linguísticas), competência textual (habilidade de construir textos coesos e coerentes), competência discursiva (habilidade de transitar por diferentes gêneros), competência sociolinguística (habilidade de lidar com regras socioculturais de uso da língua). Em última instância, desenvolver a competência comunicativa tem relação com desenvolver o letramento como prática social - envolvendo leitura e escrita (com foco na diversidade de gêneros textuais que circulam na sociedade), além de reflexão sobre a língua(gem). (SIQUEIRA, 2016, p. 47, grifos nossos). ${ }^{16}$
\end{abstract}

Como já deixamos antever, nossa linha argumentativa vai na direção sugerida por Azeredo de que a linguagem tem um tríplice papel: é forma de organização e representação do conhecimento e de nossas experiências no mundo, e também é instrumento de codificação, além de forma de interação, caracterizando-se, assim, por uma natureza cognitivo-comunicativa que se manifesta como atividade social. Nessa ótica, fica implicado o caráter dinâmico da língua, que está em constante variação e mudança, nas diferentes situações comunicativas, no tempo e no espaço. O papel multifacetado da linguagem descrito por Azeredo não é incompatível com as direções dos estudos linguísticos apontadas

\footnotetext{
${ }^{16}$ Essa definição do termo competência comunicativa se inspira na definição formulada por Travaglia (2016) para o Glossário CEALE (Centro de Alfabetização, Leitura e Escrita), da Faculdade de Educação da UFMG.
} 
por Castilho (cf. Quadro 3): a língua pode ser vista como conjunto de processos estruturantes e também de produtos estruturados, que mudam ao longo do tempo; dentre esses últimos, um se destaca pelo valor social que lhe é atribuído: a norma culta.

Acreditamos que o encaminhamento que está sendo dado a este texto vai oferecendo elementos que justificam nossa resposta negativa à questão 2 , que foi reapresentada no início desta seção. Tenhamos, pois, isso em mente ao acompanhar a exposição a seguir.

Ao se situar a língua em seu contexto social, ganham relevo os seguintes aspectos: (i) ao lado de uma realidade dinâmica que propicia emergência de novos usos linguísticos, há uma realidade estável de formas e significados/funções ${ }^{17}$ relacionadas, regularmente estruturadas e relativamente fixadas; (ii) a relação forma/função é depreendida a partir do funcionamento interligado dos níveis (morfo)sintático-semântico-discursivo;(iii) consequentemente, é preciso ultrapassar o nível da sentença e observar o funcionamento da gramática no texto/discurso; ${ }^{18}$ (iv) a competência comunicativa, que implica o domínio de recursos linguísticos (gramaticais/textuais) que tornem os interlocutores hábeis na utilização da língua em diferentes instâncias discursivas, tem lugar de destaque.

Considerando o Quadro 3, o item (i) acima nos autoriza a olhar analiticamente para as formas/funções linguísticas como processos (foco da gramática funcional e da gramática histórica) e também como produtos (foco da gramática descritiva e também da gramática histórica). Os itens (ii) e (iii) remetem diretamente à gramática funcional. O item (iv) coloca em tela também a questão da norma gramatical, tendo em vista a necessidade de adequação a diferentes contextos comunicativos, acenando assim para a gramática normativa, que entra no circuito escolar com vistas ao ensino de uma variedade linguística que é socialmente prestigiada: a norma culta.

Como lidar, na prática, com a ideia de que a linguagem desempenha papeis multifacetados? Que a língua pode ser vista como processos mentais estruturantes, ou como produtos estruturados, ou como conjunto de processos e de produtos que mudam ao longo do tempo, ou como conjunto de bons usos, no sentido de adequação? Uma saída para dar conta dessa complexidade é lidar com a noção ampla de gramática do uso, de natureza funcional, que engloba tanto formas linguísticas regularizadas como formas de uso emergente e em processo de mudança rumo à regularização, as quais são sensíveis a

\footnotetext{
${ }_{17}$ Para os efeitos deste artigo, os termos "significado" e "função" estão sendo usados indistintamente como contraparte de "forma".

18 Em termos gerais, pode-se dizer que discurso corresponde a atividades comunicativas em que experiências subjetivas do mundo são transformadas em significados socialmente compartilhados; nessas atividades, os interlocutores empregam "recursos da língua para combinar ou encadear palavras e frases em unidades de significado discursivamente relevantes: os textos" (AZEREDO, 2008, p. 69). Em suma, discurso é a língua posta em uso, materializada em textos.
} 
pressões externas e internas da língua. No escopo de uma abordagem de gramática do uso, conforme a entendemos, para além de aspectos funcionais, há espaço para aspectos descritivos e históricos ${ }^{19}$, que levam em conta fenômenos de variação e/ou mudança, além de aspectos prescritivos, nos termos de Castilho (2010).

A noção de gramática do uso, conforme caracterizada no parágrafo anterior, não se encontra cabalmente codificada e sistematizada num compêndio gramatical específico. Ela atravessa, sob diferentes prismas, especialmente as obras de Neves (2000), Azeredo (2008), Castilho (2010) e Bagno (2011), que foram brevemente apresentadas na seção precedente. Essa é uma das razões pelas quais acreditamos que o professor de Língua Portuguesa não deve ficar dependente de uma determinada concepção de linguagem/ língua e de gramática, nem de um manual específico, mesmo que este seja explicitamente de orientação linguística, e não de tradição gramatical normativista.

Observe-se que, ao priorizarmos compêndios gramaticais embasados em teorias linguísticas como os acima mencionados, não estamos excluindo, da bagagem do professor, as gramáticas normativas tanto de viés mais tradicional como as de viés mais moderno. Acreditamos que a formação do professor de Língua Portuguesa deve incluir diferentes abordagens gramaticais, para que ele tenha mais clareza e segurança acerca de sua visão de linguagem/língua e de gramática e do posicionamento que deve assumir em sala de aula. É fato que só se pode criticar algo que minimamente se conhece - no caso, por exemplo, de gramáticas normativas que apresentam caráter dogmático em defesa de uma "norma curta".

Por fim, cabe destacar que essa noção ampla de gramática do uso não é uma novidade proposta por nós. O que buscamos, nesta seção, foi dar uma certa sistematicidade a um conjunto de ideias que convergem para essa direção. Em alguma medida, esse olhar mais integrado para os fenômenos linguísticos pode ser encontrado em trabalhos acadêmicos que se voltam para o estudo de fenômenos gramaticais específicos, como alguns que integram as coletâneas organizadas por: Christiano, Silva e da Hora (2004), Funcionalismo e gramaticalização: teoria, análise, ensino; Silva, da Hora e Christiano (2006), Linguística e práticas pedagógicas; Furtado da Cunha e Tavares (2007), Funcionalismo e ensino de gramática; Silva (2007), Ensino de português: demandas teóricas e práticas; Martins e Tavares (2013), Contribuições da Sociolinguística e da Linguística Histórica para o ensino de Língua Portuguesa; Martins, Vieira e Tavares (2014), Ensino de português e sociolinguística; Vieira e Brandão (2014), Ensino de gramática: descrição e uso; Freitag e Damaceno (2015),

\footnotetext{
${ }^{19}$ Lembramos que histórico, na perspectiva de Castilho (2010), alia descritivo e funcional; mas pode
} também aliar descritivo e formal. 
Livro didático - gramática, leitura e ensino de Língua Portuguesa: contribuições para a prática docente; Faraco e Zilles (2015), Pedagogia da variação linguística: língua, diversidade e ensino. Além desses trabalhos, outras publicações com enfoque teórico-conceitual e metodológico convergente com o que foi explorado neste texto podem ser mencionadas: Neves $(2013 ;$ 2015), Texto e gramática; e Que gramática estudar na escola? Norma e uso na Língua Portuguesa; Antunes (2007; 2014), Muito além da gramática: por um ensino de línguas sem pedras no caminho; e Gramática contextualizada: limpando o pó das ideias simples.

\section{Algumas implicações pedagógicas}

Nas seções anteriores, discutimos aspectos concernentes a que gramática ensinar e para que ensinar. Sugerimos que (i) se opere com uma gramática do uso, que envolve, a depender da situação, aspectos descritivos, funcionais, históricos e/ou normativos; e que (ii) se tenha como finalidade desenvolver a competência comunicativa, criando condições para a formação do aluno como sujeito-cidadão. Cabe agora alguma reflexão sobre como ensinar.

Tomamos, como ponto de partida, os PCN, que recomendam considerar a realidade sócio-histórica e cultural dos alunos e estimulá-los a refletir criticamente sobre a língua em suas diferentes instâncias de uso:

[n]o caso do ensino de Língua Portuguesa, considerar a condição afetiva, cognitiva e social do adolescente implica colocar a possibilidade de um fazer reflexivo, em que não apenas se opera concretamente com a linguagem, mas também se busca construir um saber sobre a língua e a linguagem e sobre os modos como as opiniões, valores e saberes são veiculados nos discursos orais e escritos. (BRASIL, 1998, p. 47, grifos nossos).

Ainda de acordo com o documento: faz-se necessário que o sujeito seja "capaz de utilizar a língua de modo variado, para produzir diferentes efeitos de sentido e adequar o texto a diferentes situações de interlocução oral e escrita." (BRASIL, 1998, p. 23). Portanto, é dentro dessas condições que o ensino de gramática deve ser planejado: uso $\rightarrow$ reflexão $\rightarrow$ uso, com atividades voltadas à reflexão gramatical com base no uso efetivo da língua, as quais repercutirão em novos usos. Nesse sentido, "o texto produzido pelo aluno, seja oral ou escrito, permite identificar os recursos linguísticos que ele já domina e os que precisa aprender a dominar, indicando quais conteúdos precisam ser tematizados.” (BRASIL, 1998, p. 37). 
As atividades de natureza reflexiva requerem planejamento de situações didáticas que permitam aos alunos

operar sobre a própria linguagem, construindo pouco a pouco [...] paradigmas próprios da fala de sua comunidade, colocando atenção sobre similaridades, regularidades e diferenças de formas e de usos linguísticos, levantando hipóteses sobre as condições contextuais e estruturais em que se dão. (BRASIL, 1998, p. 27-28, grifos nossos).

A direção uso $\rightarrow$ reflexão $\rightarrow$ uso envolve diferentes tipos de atividades: linguísticas, epilinguísticas e metalinguísticas. A atividade linguística é "nada mais que o exercício pleno, circunstanciado, intencionado e com intenções significativas da própria linguagem” (FRANCHI, 2006, p. 95). Está presente nas trocas comunicativas cotidianas e, na escola, nas diferentes formas de interação, seja ao falar, ouvir, ler ou produzir textos. Por atividade epilinguística "se entendem processos e operações que o sujeito faz sobre a própria linguagem" (BRASIL, 1998, p. 28). Tais operações correspondem a atividades de reflexão, que envolvem um jogo de construções, comparação de formas, escolhas lexicais, exploração de novas formas de dizer etc., constituindo-se em ponto de partida para um trabalho de sistematização gramatical. Por atividade metalinguística "se entendem aquelas que se relacionam à análise e reflexão voltada para a descrição, por meio da categorização e sistematização dos conhecimentos, formulando um quadro nocional intuitivo que pode ser remetido a construções de especialistas” (BRASIL, 1998, p. 28). Esses tipos de atividades, feitas a partir de textos (orais ou escritos), é que devem nortear, gradativamente, as aulas sobre tópicos gramaticais, envolvendo a participação reflexiva e crítica dos alunos.

Entre as orientações para o trabalho didático, destacam-se as seguintes: (i) isolamento, entre os diversos componentes da expressão oral ou escrita, do fato linguístico a ser estudado, tomando como ponto de partida as capacidades já dominadas pelos alunos; (ii) construção de um corpus representativo para que o aluno possa perceber o que é regular e promover o agrupamento dos dados a partir de critérios construídos; (iii) apresentação da metalinguagem, após diversas experiências de manipulação e exploração do aspecto selecionado; (iv) exercitação sobre os conteúdos estudados, para que o aluno se aproprie das descobertas realizadas; (v) reinvestimento dos diferentes conteúdos exercitados em atividades mais complexas, na prática de escuta e de leitura ou na prática de produção de textos orais e escritos. (BRASIL, 1998, p. 79; adaptado).

A título de breve ilustração, tomemos como fato linguístico o uso dos pronomes pessoais nós e a gente. Um corpus interessante que pode ser organizado com os próprios 
alunos é a seleção de tirinhas que apresentem usos desses pronomes (cf. ilustração anexa). Os alunos, divididos em grupos, fazem o levantamento dos itens, observam os contextos de uso deles considerando, por exemplo: se estão expressos ou apagados; como se dá a concordância verbal; a relação do apagamento com a concordância; a referência específica e genérica (quais são as pessoas referidas); quais personagens usam uma e outra forma; se um mesmo personagem usa sempre a mesma forma; que características têm esses personagens etc. $\mathrm{O}$ professor, como mediador, vai problematizando e organizando com a turma essas informações, criando condições para que os alunos aprendam a pesquisar, observando, separando e classificando itens da língua numa prática construída com e pelos sujeitos que dela participam.

Como desdobramentos da atividade, os alunos podem buscar textos de diferentes gêneros, veiculados em material impresso ou digital, mensagens de WhatsApp, Facebook, etc., e continuar agrupando os dados de acordo com os critérios já construídos ou acrescentando novos, se for o caso. Esse é um momento de reflexão linguística, de problematização, mais do que de atividade metalinguística.

Na sequência, uma atenção especial deve ser dada ao quadro de pronomes pessoais presente em manuais e livros didáticos. Uma atividade importante é observar se o pronome a gente integra os quadros consultados e problematizar esse aspecto. Apontar o caráter inovador desse item, mostrando seu percurso na língua: a gente resulta do substantivo gente, por isso a concordância verbal com forma de terceira pessoa do singular. Cabe ao professor orientar o trabalho de modo a concluírem que se trata de um caso de variação linguística, que ambos os pronomes fazem parte da norma culta da língua, mas que diferem, por exemplo, quanto ao nível de formalidade (nós é mais formal e a gente menos formal) e quanto à modalidade (nós é mais característico da escrita e a gente da oralidade), embora a gente também apareça na escrita (ver crônicas e quadrinhos, por exemplo). Uma proposta mais detalhada para o trabalho com pronomes pessoais é apresentada, no formato de oficina, em Siqueira (2016).

Pode ser de grande valia, nesse momento, explorar a ideia de contínuos de variação, propostos por Bortoni-Ricardo (2005), considerando o continuum rural-urbano, o de oralidade-letramento e o de monitoração estilística. Para uma descrição geral do uso dos pronomes nós e a gente, o professor pode se valer do trabalho de Vianna e Lopes (2015), que fazem um mapeamento desses usos em diversas regiões brasileiras. Sobre os paradigmas pronominais - o tradicional e o em uso efetivo no $\mathrm{PB}$-, sugerimos conferir o artigo de Görski e Coelho (2009), que abordam a variação linguística e o ensino de gramática e apresentam sugestões metodológicas para o estudo dos pronomes. 
Observe-se, na breve ilustração apresentada, que há aspectos descritivos, funcionais, históricos e normativos (cf. Quadro 3) em jogo, nesses últimos quando se trata de adequação de uso.

\section{Considerações finais}

Reportando-nos à primeira questão formulada na Introdução (É necessário que o professor tenha conhecimento de diferentes concepções de linguagem, de língua e de gramática?), acreditamos ter evidenciado a razão da resposta afirmativa sugerida. Sim, o professor de Língua Portuguesa deve ter clareza (i) de que os termos linguagem, língua e gramática são, no mínimo, polissêmicos, já que remetem a diferentes perspectivas teórico-conceituais; (ii) de que a dada concepção de linguagem se atrela uma certa concepção de língua e também um certo tipo de gramática; (iii) de que gramática normativa, embora tenha alguma relação com gramática tradicional, não equivale a esta; (iv) de que as diferentes concepções de linguagem/língua/gramática devem orientar diferentes práticas no que se refere ao ensino.

Na sequência, discorremos em torno de o que, para que e como ensinar. Retomando a segunda questão (É necessário que o professor assuma uma dada concepção de gramática, de linguagem e de língua e que paute suas aulas exclusivamente por essa concepção?), justificamos nossa resposta negativa sugerindo que uma abordagem ampla de gramática do uso que abarque aspectos conceituais de diferentes teorias linguísticas que tomam como objeto a língua em seu dinamismo seria mais adequada para dar conta da complexidade que envolve os fenômenos gramaticais. Consideramos, pois, que aspectos descritivos, funcionais, históricos e normativos devem ser contemplados no âmbito de uma gramática do uso. Nesse sentido, as atividades pedagógicas propostas para o ensino de gramática devem envolver: a visão de língua como sistema heterogêneo sócio-historicamente constituído; a tensão entre estabilidade e instabilidade nas relações entre formas e funções; a concepção de ensino de gramática contextualizada; entre outros aspectos.

Considerando que o para que ensinar gramática focalizou o desenvolvimento da competência comunicativa tendo em vista a formação de um sujeito-cidadão, o como ensinar voltou-se para uma pedagogia colaborativa em que o professor oferece condições para que os alunos desenvolvam atividades linguísticas, epilinguísticas e metalinguísticas, baseadas no uso $\rightarrow$ reflexão $\rightarrow$ uso.

Esperamos que o presente texto contribua para tomadas de posição em relação ao controverso tema do ensino de gramática e que suscite novas reflexões e questionamentos acerca das relações, nem sempre tranquilas, entre teoria e prática. 


\section{Referências}

ANTUNES, I. Muito além da gramática: por um ensino de línguas sem pedras no caminho. São Paulo: Parábola, 2007.

ANTUNES, I. Gramática contextualizada: limpando o pó das ideias simples. São Paulo: Parábola, 2014.

AZEREDO, J. C. Gramática Houaiss da Língua Portuguesa.2. ed. São Paulo: Publifolha, 2008.

BAGNO, M. Dramática da Língua Portuguesa: tradição gramatical, mídia; exclusão social. 2. ed. São Paulo: Edições Loyola, 2001.

BAGNO, M.Gramática pedagógica do português brasileiro.São Paulo; Parábola Editorial, 2011.

BARBOSA, A. G. Saberes gramaticais na escola. In: VIEIRA, S. R.; BRANDÃO, S. F. (Org.), 2a ed., 2014. p. 31-54.

BECHARA, E. Moderna gramática portuguesa. 37. ed. Revista e Ampliada. Rio de Janeiro: Lucerna, 2001.

BORTONI-RICARDO, S. M. Nós cheguemu na escola, e agora? Sociolingüística e Educação. São Paulo: Parábola Editorial, 2005.

BRASIL. Secretaria de Educação Fundamental. Secretaria de Educação Fundamental. Parâmetros curriculares nacionais: terceiro e quarto ciclos do ensino fundamental: Língua Portuguesa. Brasília (DF): MEC/SEF, 1998.

CASTILHO, A. T. de. Nova gramática do Português Brasileiro. São Paulo: Contexto, 2010.

CHRISTIANO, M. E. A., SILVA, C. R.; HORA, D. (Org.). Funcionalismo e gramaticalização: teoria, análise, ensino. João Pessoa: Ideia, 2004.

CHOMSKY, N. Syntactic Structures. The Hague/Paris: Mouton, 1957.

. Knowledge of language: its nature, origin and use. New York: Praeger, 1986.

CUNHA, C.; LINDLEY CINTRA, L. F. Nova gramática do portuguêscontemporâneo. Rio de Janeiro: Nova Fronteira, 1985.

FARACO, C. A. Norma culta brasileira: desatando alguns nós. 2. ed. São Paulo: Parábola, 2008.

; ZILLES, A. M. S. Pedagogia da variação linguística: língua, diversidade e ensino. São Paulo: Parábola, 2015.

FRANCHI, C. Criatividade e gramática. In POSSENTI, S. (Org.). Mas o que é mesmo 'gramática'? São Paulo: Parábola, 2006. p. 34-101.

FREITAG, R. M. K.; DAMACENO, T. M. S. S. Livro didático - gramática, leitura e ensino de Língua Portuguesa: contribuições para a prática docente. São Cristovão: Editora UFS, 2015. 
FURTADO DA CUNHA, M. A.; TAVARES, M. A. Linguística funcional e ensino de gramática. In: . (Org.). Funcionalismo e ensino de gramática. Natal/RN: EDUFRN, 2007. p.13-51.

GERALDINE, J. W. (Org.). O texto na sala de aula. Cascavel: Assoeste, 1984.

GIVÓN, T. The functional approach to language and the typological approach to grammar. In: Syntax: an Introduction. v.1. Amsterdam/Philadelphia: J. Benjamins, 2001.

GÖRSKI, E. M.; FREITAG, R. M. K. Língua materna e ensino: alguns pressupostos para a prática pedagógica. In SILVA, Camilo Rosa (org.) Ensino de português: demandas teóricas e práticas. João Pessoa: Idéia, 2007. p. 91-125.

GÖRSKI, E. M.; FREITAG, R. M. K. O papel da Sociolinguística na formação dos professores de Língua Portuguesa como língua materna. In: MARTINS, M.A.; TAVARES, M. A. (Org.), 2013. p. 13-52.

GÖRSKI, E. M.; COELHO, I. L. Variação linguística e ensino de gramática. Working Papers em Linguística, v. 10, 2009.p. 73-91.

HOPPER, P. J. Emergent grammar. BLS, v. 13, pp. 139-57, 1987.

Press, 2003.

; TRAUGOTT, E. Grammaticalization. 2 ed. Cambridge: Cambridge University

KOCH, I. V. A Inter-ação pela Linguagem. São Paulo: Contexto, 1992.

LABOV, W. Padrões sociolingüísticos. Trad. de M. Bagno; M. M. P. Scherre; C. R. Cardoso. São Paulo: Parábola Editorial, 2008 [1972].

LOBATO, L. M. P. Sintaxe gerativa do português: da teoria padrão à teoria da regência e ligação. Belo Horizonte: Vigília, 1986.

MARTINS, M. A. (Org.). Gramática e ensino.Natal, RN: EDUFRN, 2013.

; TAVARES, M. A. (Orgs.). Contribuições da Sociolinguística e da Linguística Histórica para o ensino de Língua Portuguesa. Coleção Ciências da Linguagem Aplicadas ao Ensino, volume V. Natal, RN: EDUFRN, 2013. p. 11-52.

; VIEIRA, S. R. TAVARES, M. A.; (Org.). Ensino de português e sociolinguística. São Paulo: Contexto, 2014.

MATTOS E SILVA, R. V. Tradição gramatical e gramática tradicional. São Paulo: Contexto, 1989.

NEVES, M. H. M. Gramática de usos do português. São Paulo: UNESP, 2000.

. A gramática: história, teoria e análise, ensino. São Paulo: Editora UNESP, 2002. . Texto e gramática. 2. ed. São Paulo: Contexto, 2013.

. Que gramática estudar na escola? Norma e uso na Língua Portuguesa. 4. ed. São Paulo: Contexto, 2015.

PERINI, M. A. Princípios de linguística descritiva: introdução ao pensamento gramatical. 
São Paulo: Parábola, 2006.

. Gramática do português brasileiro. São Paulo: Parábola, 2010.

PILATI, E. Linguística, gramática e aprendizagem ativa. Campinas, SP: Pontes Editores, 2017.

PIRES DE OLIVEIRA, R.; QUAREZEMIN, S. Gramáticas na escola. Petrópolis: Vozes, 2016.

POSSENTI, S. Por que (não) ensinar gramática na escola. São Paulo: Mercado de Letras, 1996.

SANTA CATARINA. Governo do Estado. Proposta curricular de Santa Catarina: formação integral na educação básica. Estado de Santa Catarina. Secretaria de Estado da Educação, 2014.

SILVA, C. R.; HORA, D. da; CHRISTIANO, M. E. (Orgs.). Linguística e práticas pedagógicas. Santa Maria: Pallotti, 2006.

SILVA, C. R. (Org.). Ensino de português: demandas teóricas e práticas. João Pessoa: Ideia, 2007.

SIQUEIRA, M. A. A. da R. O ensino de gramática a partir da língua em uso: por uma prática voltada ao desenvolvimento da competência comunicativa dos alunos. Florianópolis, 2016. Dissertação de Mestrado. Programa de Mestrado Profissional em Letras. Universidade Federal de Santa Catarina.

TRAVAGLIA, L. C. Gramática e interação: uma proposta para o ensino de gramática no $1^{\circ}$ e $2^{\circ}$ graus. São Paulo: Cortez, 2009.

Competência comunicativa. Glossário CEALE. Disponível em: http://ceale. fae.ufmg.br/app/webroot/glossarioceale/verbetes/competencia-comunicativa. Acesso em: 20 jun. 2016.

VIANNA, J.B. S.; LOPES, C. R. S. Variação dos pronomes “nós” e "a gente”. In: MARTINS, M. A.; ABRAÇADO, J. (Org.). Mapeamento sociolinguístico do português brasileiro. São Paulo: Contexto, 2015. p. 109-131.

VIEIRA, S. R.; BRANDÃO, S. F. Ensino de gramática: descrição e uso. 2. ed. São Paulo: Contexto, 2014.

VIEIRA, S. R. Três eixos para o ensino de gramática: uma proposta experimental. In: NORONHA, C. A.; SÁ JR., L. A. de. (Org.) Escola, ensino e linguagem [recurso eletrônico]. Natal-RN, EDUFRN, 2017. Disponível em: http://repositorio.ufrn.br. Acesso em: 20 de julho de 2017.

Data de submissão: 25/07/2017

Data de aceite: $13 / 11 / 2017$ 
$\operatorname{Anexos}^{20}$
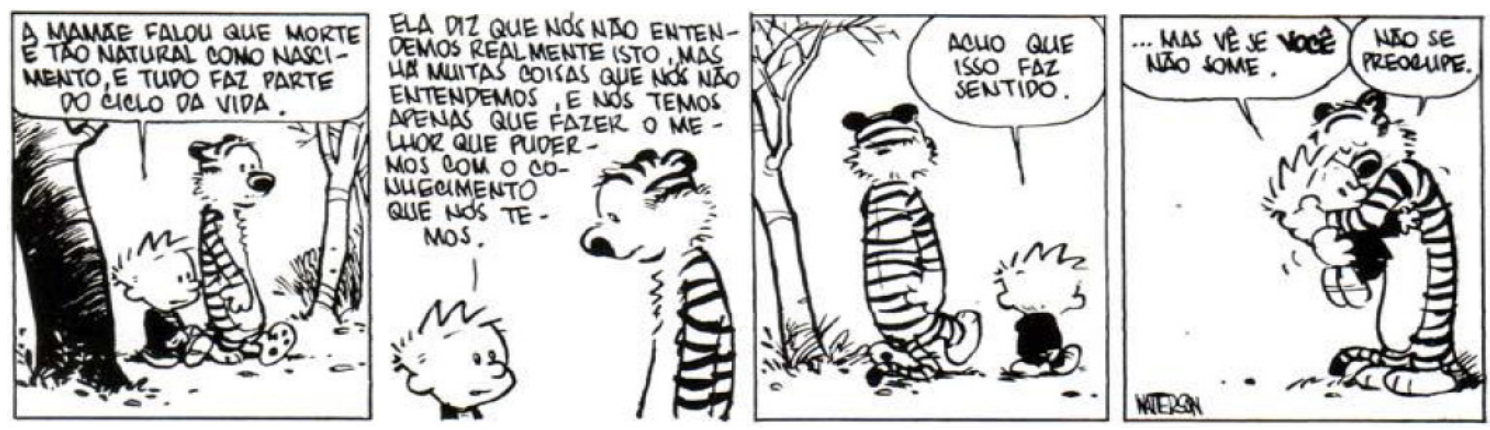

Anexo 1. Nós (referência genérica)

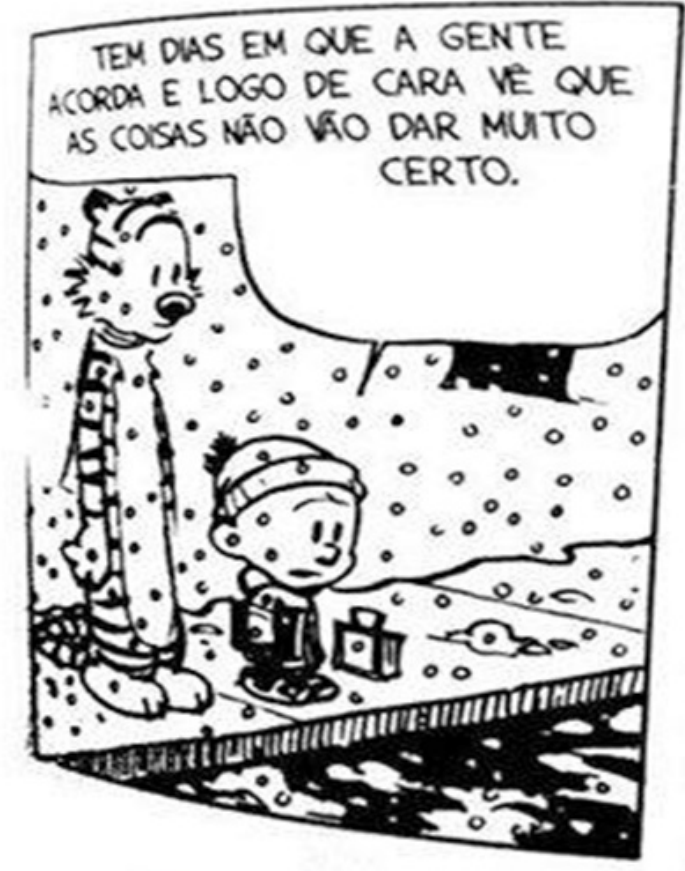

E O TIPO DE OCASIÃO EM QUE

A GENTE DEMA VESTIR DE NOVO O PUAAMA FAZER UM CHOCOLATE QUENTE E FICAR LENDO GIBIS NA CAMA ATE O MUNDO VOLTAR A SER UM LUGAR MENOS HOSTIL.

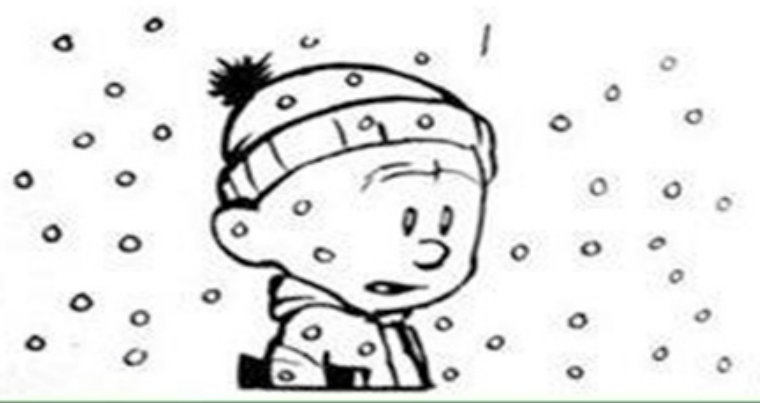

Anexo 2. A gente (referência genérica)

\footnotetext{
${ }^{20}$ Tirinhas Calvin/Haroldo, de Bill Watterson. Vários tradutores. Disponível em: <http://www.lojaconrad.
} com.br/lojas/conrad/__home.cfm?inputBusca=calvin\&paginatual=1\#>. Acesso em: 28 out. 2016. 

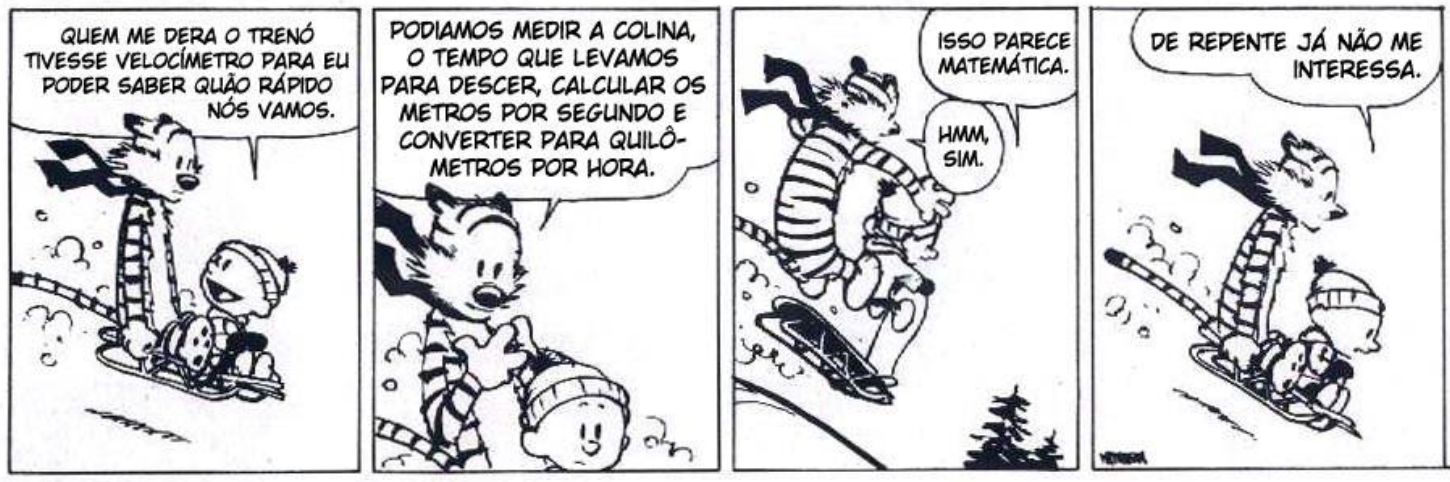

Anexo 3. Nós (referência específica)
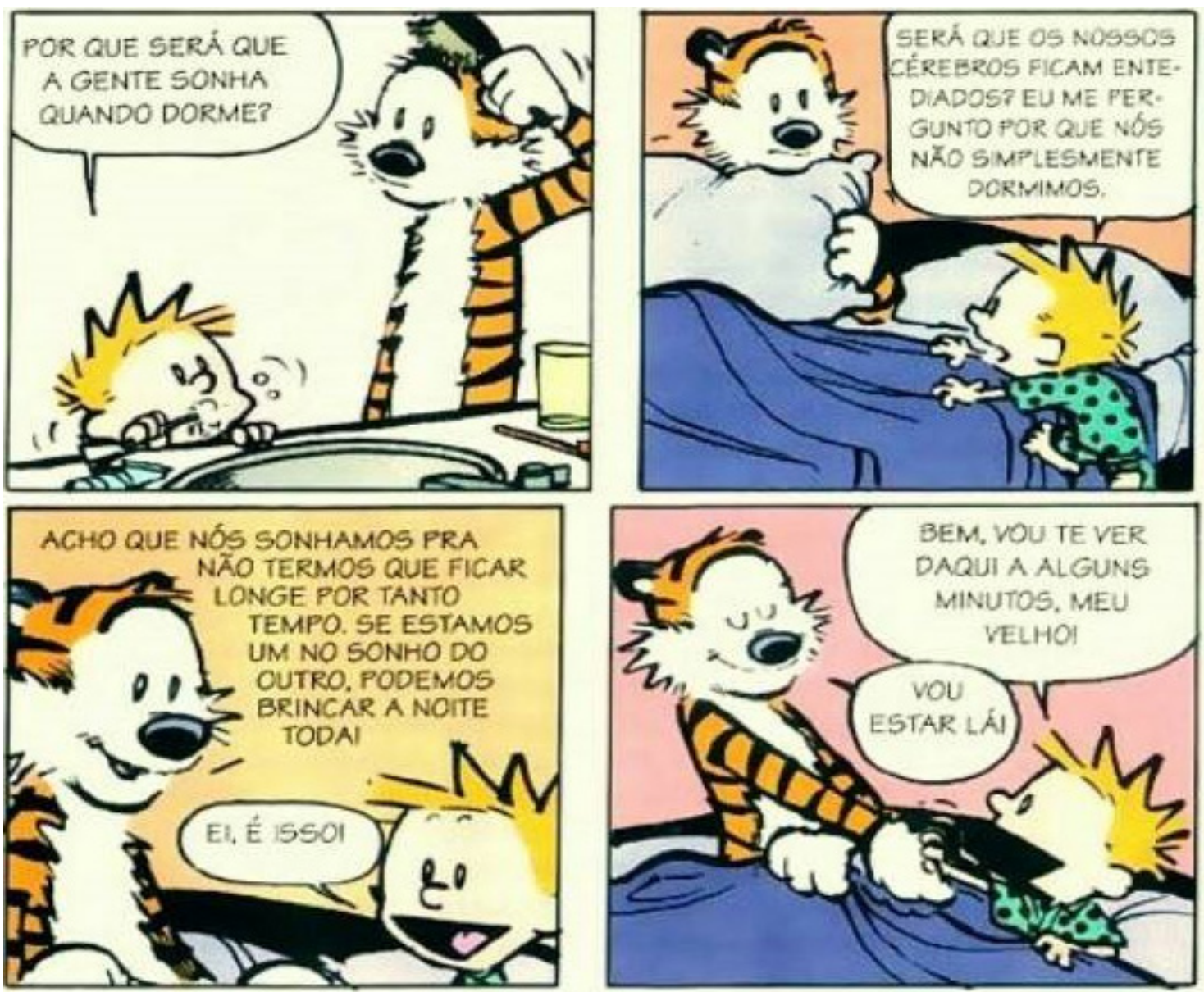

Anexo 4. A gente/nós (referência genérica) 